\title{
UNIVERSITYOF
}

FORWARD

THINKING

WESTMINSTER用

WestminsterResearch

http://www.westminster.ac.uk/westminsterresearch

\section{Body fat MRS}

Thomas E. Louise and Bell Jimmy D.

This is the peer reviewed version of the following article: Thomas E. Louise and Bell Jimmy D. (2015) Body fat MRS, eMagRes 4 (3) 663-672, which has been published in final form at https://dx.doi.org/10.1002/9780470034590.emrstm1478.

This article may be used for non-commercial purposes in accordance with Wiley Terms and Conditions for Self-Archiving.

The WestminsterResearch online digital archive at the University of Westminster aims to make the research output of the University available to a wider audience. Copyright and Moral Rights remain with the authors and/or copyright owners.

Whilst further distribution of specific materials from within this archive is forbidden, you may freely distribute the URL of WestminsterResearch: ((http://westminsterresearch.wmin.ac.uk/).

In case of abuse or copyright appearing without permission e-mail repository@westminster.ac.uk 


\subsection{Body Fat MRS}

E Louise Thomas and Jimmy D Bell

Department of Life Sciences,

University of Westminster,

115 New Cavendish Street,

London

W1W 6UW

Tel: 02035064608

Email: E.Thomas1@westminster.ac.uk or J.Bell@westminster.ac.uk

Dr E Louise Thomas obtained her PhD in vivo ${ }^{13} \mathrm{C}$ MRS from the University of London in 1996. She worked for many years at the Robert Steiner MRI Unit at the Hammersmith Hospital on the development and application of in vivo MR techniques to the study of adipose tissue composition, content and distribution. She has also worked extensively on the non-invasive study of ectopic fat, particularly liver fat and has published over 80 peerreviewed articles in this area. She has recently been appointed as a Senior Lecturer at the University of Westminster.

Professor Jimmy D Bell completed his PhD in Biochemistry in 1987 (London). He has worked extensively on the development and application of in vivo MR techniques for the study of disease development, with especial focus on adipose tissue and liver metabolism. He joined the MRC Clinical Sciences Centre (Imperial College London) in the mid-1990s, where he was appointed Group Head. He recently moved to the University of Westminster to establish a new Research Centre for Optimal Health (ReCOH). He has published over 190 peer-reviewed papers and authored over a dozen chapters for scientific books.

Keywords: body fat, adipose tissue, magnetic resonance imaging, magnetic resonance spectroscopy; bone marrow; visceral; subcutaneous; 


\section{Abstract}

The increasing levels of obesity, and its associated co-morbidities, have prompted a reassessment of the techniques used for assessing body fat, including content, distribution and composition. Magnetic resonance spectroscopy (MRS) is amongst the many invaluable in vivo tools available today to evaluate the role of body fat in health and disease. However, although MRS has become a powerful technique for assessing ectopic fat in vivo, it has had limited use in other areas of research associated with body fat. MRS has found some success as a fast method to determine whole body adiposity in rodent models of disease, as well as a noninvasive method of obtaining an index of the overall composition of body fat in human subjects. Its more significant use has been in the understanding of bone marrow fat content, where important advances have been made, especially in longitudinal studies. In conclusion, in the area of body fat, MRS continues to be an adjunct technique to more precise and versatile MRI methods. 


\section{Introduction}

Obesity has become an important public health concern and significant resources are being channeled towards understanding the role of adipose tissue (body fat) and ectopic fat in the development of obesity-related co-morbidities. Accurate measurements of body fat content and distribution, in a fast and reproducible manner, have become increasingly important in both human and animal studies.

There are a number of methods available to evaluate body fat content (and distribution). Conventional methodologies include indirect methods based on anthropometry (body mass index, BMI; waist and hip circumference), skin-fold measurements, bioelectrical appearance, underwater weighing and air plesmography, while more direct methods include imaging technology such as computer tomography/dual-energy-X-ray absorptiometry (CT/DXA) and magnetic resonance imaging $(\mathrm{MRI})^{1}$. While $\mathrm{MRI}$ has become the gold standard for measuring body fat content and distribution ${ }^{2}$, the large number of images generated, particularly from whole body scans, together with the lack of fast, affordable and automated methods of analysis, has driven the search for faster more efficient methods of data acquisition and analysis.

Magnetic resonance spectroscopy (MRS) has been proposed as a simple alternative to assess body fat content, distribution and composition in human subjects and animal models. In this chapter we will review the pros and cons of this approach and 
give examples of where this technique can provide valuable information in basic and clinical research.

MRS has been applied in a number of ways to assess body fat:

1. To assess the composition of adipose tissue (AT)

2. As a measure of whole body adiposity

3. To measure ectopic fat content in lean tissue (muscle, liver, heart, pancreas and kidneys)

4. For assessing bone marrow adipose tissue (MAT) content

5. To discriminate between white (WAT) and brown adipose tissue (BAT)

\subsection{Composition of Adipose Tissue}

\subsection{In vivo ${ }^{13} \mathrm{C}$ MRS of adipose tissue}

It is well established that the distribution of AT is associated with incidence of coronary heart disease (CHD), but there is also considerable interest in the association between AT composition and disease. Previous studies have shown that low levels of unsaturation (long-chain polyunsaturated fatty acids n-3 and n6) in the AT are associated with increased risk of $\mathrm{CHD}^{3}$. Moreover, there is a progressive inverse relationship between linoleic acid AT reserves, platelet membrane eicosapentaenoic acid (EPA) and risk of angina pectoris, independent of traditional CHD risk factors ${ }^{4}$. 
Examination of the fatty acid (FA) composition of AT has traditionally required samples obtained by biopsy or at post-mortem for in vitro analysis by gas liquid chromatography (GLC) following chemical extraction. However, routine assessment of lipid composition by repeated biopsy invokes both ethical and practical difficulties, limiting its use in serial studies, as for example examining longitudinal dietary effects on AT composition. Similarly, exploration of deeper AT depots, such as intra-abdominal AT ("visceral fat"), are not feasible using this invasive methodology.

Non-invasively, the main in vivo MR technique to assess AT composition has been ${ }^{13} \mathrm{C}$ MRS. The low natural abundance of ${ }^{13} \mathrm{C}$ (only $1.1 \%$ compared with the more abundant ${ }^{12} \mathrm{C}$ isotope), has restricted its application mainly to the more expensive ${ }^{13} \mathrm{C}$-isotope enrichment studies (see emrstm1841/1468). However, even at the level of natural abundance there is sufficient ${ }^{13} \mathrm{C}$ within adipose tissue, to make non-enriched ${ }^{13} \mathrm{C}$ MRS possible. A typical ${ }^{1} \mathrm{H}$-coupled ${ }^{13} \mathrm{C}$ spectrum from the subcutaneous AT of the thigh of a healthy volunteer is shown in Figure 1. Over 25 signals can be clearly discerned, all arising from the carbon atoms within the acyl-chain of the triglyceride molecules stored within adipocytes, the main cellular component of AT. Signal from other lipids, including cholesterol and phospholipids cannot be normally detected by in vivo ${ }^{13} \mathrm{C}$ of $\mathrm{AT}$, as these cellular components are normally tightly packed within membrane structures and/or bound to macromolecules, making them "invisible" to standard MRS techniques (Table 1).

\section{<Figure 1 near here>}


$<$ Table 1 near here>

To date the main application of in vivo ${ }^{13} \mathrm{C}-\mathrm{MRS}$ has been to examine the longterm effects of diet on the composition of AT in rodents $s^{5,6}$ and humans ${ }^{7-10}$. As early as 1983, Canioni et al showed that modulation of essential fatty acids in the diet of rats altered the ${ }^{13} \mathrm{C}-\mathrm{MR}$ spectrum of adipose tissue ${ }^{5}$. Chronic restriction resulted in a decrease of resonances arising from polyunsaturated fatty acids, while supplementation resulted in a significant increase. From this they postulated that the polyunsaturated peak at $128.5 \mathrm{ppm}$ in the decoupled spectrum (corresponding to peaks 3 and 5 in the coupled version in Figure 1) could be used as a non-invasive biomarker of dietary polyunsaturated fat intake ${ }^{5}$. Similarly Fan et al showed that the spectra of adipose tissue from rats fed either olive, safflower or menhaden oil for 17 days, was remarkable similar to the ${ }^{13} \mathrm{C}$ MR spectra from each of the oils ${ }^{6}$. Furthermore, ${ }^{13} \mathrm{C}$ MRS could be used to monitor changes in the adipose tissue profiles as the rats were switched to between the different diets ${ }^{6}$.

Studies in humans have demonstrated similar results, with ${ }^{13} \mathrm{C}$ MRS shown to be a long term biomarker of habitual dietary intake. Beckmann et al found that the level of unsaturation measured from the ${ }^{13} \mathrm{C}$ MR spectra of adipose tissue from volunteers following 6 months adherence to either a fat-reduced or high-fat diet agreed with that assessed from their subjects' dietary history ${ }^{8}$. Similarly Thomas et al reported clear differences between the adipose tissue composition of vegans, vegetarians and omnivores, which was strongly linked to the fatty acid 
composition of their habitual $\operatorname{diet}^{9}$. Interestingly, the high levels of polyunsaturated fatty acids observed in the adipose tissue of vegan subjects were negatively associated with both total and low density lipoproteins (LDL)cholesterol, suggesting that ${ }^{13} \mathrm{C}$ MRS could indeed be used as a non-invasive measure of 'metabolic health's. Similarly, Hwang et al reported significantly elevated levels of monounsaturated and polyunsaturated fatty acids from the ${ }^{13} \mathrm{C}$ MR spectra of the adipose tissue of subjects following diets supplemented with either fish oil or Lorenzo's oil (high in monounsaturated fatty acids) ${ }^{10}$.

There have also been several applications of ${ }^{13} \mathrm{C}-\mathrm{MRS}$ to diseases such as cystic fibrosis, where reduced levels of adipose polyunsaturated fatty acids have been reported $^{7,11}$. Interestingly despite GLC of adipose tissue samples revealing significant reductions in omega-3 FAs between malnourished patients prior to liver transplantation, no significant differences were found by ${ }^{13} \mathrm{C}$ MRS of adipose tissue $^{12}$. However, at the follow-up scan, 8 weeks after successful transplantation, an increase in the overall level of saturated fatty acids was observed. Whether this was a reflection of the dietary composition during this time, or an indication of unsaturated fatty acids tending to be preferentially utilized for metabolic or structural functions during this period of recovery is unclear $^{12}$.

${ }^{13} \mathrm{C}$ MRS has been further applied to the study of neonatal adipose tissue composition $^{13}$. Thomas et al showed that the fatty acids composition of infants at birth was more saturated compared with their mothers. During the first 6 weeks of 
life, there was an increase in the level of unsaturated fatty acids, though this still did not reach the levels measured in adults ${ }^{13}$.

In conclusion, ${ }^{13} \mathrm{C}$ MRS is a robust and reproducible method for the assessment of AT composition, and several studies have shown generally good agreement between in vivo ${ }^{13} \mathrm{C}$ MRS and GLC analysis of AT biopsy samples. ${ }^{7,14}$ Nevertheless ${ }^{13} \mathrm{C}$ MRS has not really been applied outside a small number of research centers. One of the main obstacles is the limited availability of ${ }^{13} \mathrm{C}$ MRS capability in most clinical and research centers. Another important issue with this technique is that although it can be used to assess overall levels of saturated, mono- and polyunsaturated FAs, it cannot distinguish between individual FAs, an important consideration given the well-established metabolic and functional differences of different FAs. Furthermore, most ${ }^{13} \mathrm{C}$ MRS studies to date have employed surface coils without localization, which generally only allows for the study of subcutaneous AT.

\section{$1.2^{1} \mathrm{H}$ MRS of adipose tissue}

More recently ${ }^{1} \mathrm{H}$-MRS has been applied to measure the composition of AT and has been shown to agree well with measurements made using GLC, particularly at longer echo times $(\mathrm{TE}=135 \mathrm{~ms})^{15} .{ }^{1} \mathrm{H}$ MRS has the advantage of utilizing routine localization sequences such as PRESS (point resolved spectroscopy) or STEAM (stimulated echo acquisition mode), allowing measurements of the composition of both subcutaneous and internal AT depots, such as visceral $A T^{16}$, the latter being metabolically more interesting than the former adipose tissue stores. It has also enabled the study of regional compositional differences within the subcutaneous AT 
depot, allowing comparisons between the composition of deep vs superficial subcutaneous AT to be made ${ }^{17}$. A typical ${ }^{1} \mathrm{H}$-spectrum from adipose tissue with associated peak assignments is shown in Figure 2.

\section{<Figure 2 near here>}

Whilst there is limited research in this area, there have been some interesting observations reported using this technique. For example Machann et al reported a significant variation in composition of visceral AT between subjects ${ }^{16}$. They also found a significant correlation between the composition and quantity of visceral AT present in different subjects, with those found to have the least volume of visceral fat having the highest unsaturated index. Similarly Lundbom et al found deeper layers of subcutaneous AT to be more saturated than more superficial layers, a change attributed to reduced mono-unsaturated fatty acids, since no differences in polyunsaturated fatty acids were observed at different depths ${ }^{17}$.

However, like with ${ }^{13} \mathrm{C}$-MRS, assessment of AT composition by ${ }^{1} \mathrm{H}$ MRS does not provide full detail of the different type of fatty acid within the triglycerides, and only enables differentiation between major classes of FA: saturated vs unsaturated, polyunsaturated vs monounsaturated etc. Thus, for identification of individual FA it is still necessary to collect biopsy samples for analysis by GLC.

Localized ${ }^{1} \mathrm{H}$ MRS has also been used in the study of the nature of cellulite within subcutaneous $\mathrm{AT}^{18}$. Deep indentation in the dermis ("cellulite") observed in some 
subjects, especially women, is frequently reported and is the focus of many resources from the cosmetic industry. Cellulite is popularly believed to arise from "water retention" within this tissue. However, the results from this ${ }^{1} \mathrm{H}$ MRS study ${ }^{18}$ do not confirm this, but rather suggest that water retention may be taking place within the connective tissue septae rather than the AT.

\subsection{Whole Body Adiposity}

Whilst most MR studies of AT have focused on using imaging-based techniques, a small number, particularly in rodent studies, have opted for the use of ${ }^{1} \mathrm{H}$ MRS. Generally, whole body measurement of fat content using ${ }^{1} \mathrm{H}$ MRS can only be made if the subject matter being scanned fits in its entirety within the transmit/receive ( $T x / R x)$ coils. Hence this method has mainly focused on the study of small animals, including rodents and poultry ${ }^{19-25}$, with some minor applications in human subjects ${ }^{26-}$ 29. One of the principal motivations for using ${ }^{1} \mathrm{H}$ MRS, compared with MRI, appears to be the speed of acquisition and the simplicity of its analysis. Indeed, a whole body ${ }^{1} \mathrm{H}$ MRS can be obtained in $<1$ second, leading generally to a spectrum consisting of just 2 peaks: water at $4.7 \mathrm{ppm}$ and fat at $1.3 \mathrm{ppm}$, and the resulting analysis is simply their ratio, Figure 3 . Compared to a whole body MRI scan, which requires significant analysis time ( $>30$ mins), ${ }^{1} \mathrm{H}$ MRS of large data sets, with its rapid acquisition and analysis, becomes extremely attractive.

\section{<Figure 3 near here>}

To date there have been several validation studies of this technique on mice ${ }^{19}$ and rats $^{21}$, where body fat content measured using whole body ${ }^{1} \mathrm{H}$ MRS has been 
compared with lipid extraction of the carcass. Good correlations and agreement were reported between MRS and extracts.

Yet, despite the excellent agreement between the ${ }^{1} \mathrm{H}$ MRS and carcass analysis, adiposity measurements by this technique are not always directly comparable to those reported by other methods, particularly MRI and CT. ${ }^{1} \mathrm{H}$ MRS measures total body fat content (principally triglycerides within the AT, although there are contributions from fat deposited in tissues such as the liver, muscle and bone marrow as well as fatty intestinal contents), while MRI is a measure of total AT volume, which is comprised of more than just triglycerides within the adipocytes, and includes contribution from water within this tissue. Water content within AT can reach as much as $30 \%$ of the total volume, especially in neonates and some disease state. Thus, caution must be taken in interpreting the fat/water ratio obtained by ${ }^{1} \mathrm{H}-\mathrm{MRS}$, as changes in the fat content detected by this technique may be a consequence of real variations in fat content - or simply reflect changes due to increases in tissue hydration or edema. Interestingly, the very difference between MRS and MRI outputs could in theory be utilized to assess changes in AT hydration, although interpretation of the results may not be straight forward.

In human subjects, the application of ${ }^{1} \mathrm{H}$ MRS has been partly hindered by the fact that without localization both magnet and embedded $T x / R x$ coils are too short to accommodate a whole subject, except neonates and young children. Furthermore, it is difficult to determine the different anatomical contributions to the overall spectrum, while field inhomogeneity beyond the central area of the magnet can lead to 
broadening of signals and distortion of the relative fat/water ratio ${ }^{26,27}$. In order to overcome some of these difficulties Weis et al used a high-speed spectroscopic imaging technique to map body fat from head-to-toe ${ }^{28}$. Spectra were obtained from several thick-slices corresponding to contiguous sections of the body, give excellent quantitation of total body fat and an additional insight into gender differences in regional fat distribution (see Figure 4).

\section{<Figure 4 near here>}

However, if the ${ }^{1} \mathrm{H}$-MRS measurements of total body fat are contrasted with those obtained by whole body MRI techniques, it can be clearly seen that in humans there is little value in its application. MRI techniques such as $T_{1}$-weighted or water-fat imaging can deliver whole body scanning in a matter of minutes and with recent advances in automated image analysis, assessment of body fat content and distribution can be achieved in most clinical scanner ${ }^{2}$. Typical whole-body coronal $\mathrm{T}_{1}$-weighted images from a series of volunteers are shown in Figure 5._Individual images were obtained $<6$ minutes and allow for content and distribution of body fat and muscle to be readily obtained with high accuracy and reproducibility. Similar results could not be readily achieved with ${ }^{1} \mathrm{H}$ MRS and thus total body fat measurements using in vivo spectroscopy will continue to be of limited used as it fails to provide sufficient information regarding body fat distribution, especially from visceral fat.

$<$ Figure 5 near here>

\subsection{Ectopic Fat}


In no other area of research has ${ }^{1} \mathrm{H}$ MRS been used as extensively as in the study of ectopic fat, including muscle, liver, heart and pancreas. Indeed, ${ }^{1} \mathrm{H}$ MRS of liver fat has become the gold standard in clinical research, especially in longitudinal studies where serial biopsies are impractical and unethical. In other areas of clinical research this is the sole technique available to determine fat content of certain organs, including the pancreas and heart, each of which produces an invaluable stream of data that continues to inform both scientific and clinical research. We will however not cover this topic in this review and point the reader to other chapters in this volume (emrstm1470, 1462, 1436, 1453) for a full description of the use of MRS in the study of ectopic fat. It should be noted however, that water-fat imaging techniques are being developed and implemented to assess ectopic fat deposits such as in liver and pancreas and are likely to be of considerable use in clinical scanners that do not have MRS capabilities ${ }^{30-32}$.

\subsection{Bone Marrow}

There is renewed interest in understanding the relationship between marrow AT (MAT) and bone function, including osteoporosis ${ }^{33}$. Osteoporosis is a chronic disorder with particularly high prevalence amongst the older population, leading to increased disability and mortality. Contrary to common perception, osteoporosis appears to be linked to obesity, with some researchers suggesting a potential causal effect. Furthermore, type-2 diabetes, which is closely associated to obesity, is also linked to increased risk of bone fracture despite normal or above average bone density. 
Bone marrow consists mainly of hematopoietic tissue ("red marrow") and fat cells ("yellow marrow" or MAT). MAT was thought for a long time to be metabolically inert; however, recent studies have begun to reassess the role of fat cell in bone, with ${ }^{1} \mathrm{H}$ MRS playing an important role in this process ${ }^{34-43}$.

A typical ${ }^{1} \mathrm{H}$ MRS spectrum from bone marrow from a healthy volunteer $(A)$ and a subject with pathology (B) can be seen in Figure 6. It consists primarily of peaks arising from water and lipids. The lipid signal itself consisting of resonances from $\mathrm{CH}_{3}$, - $\left(\mathrm{CH}_{2}\right)_{\mathrm{n}}$ - and $\mathrm{HC}=\mathrm{CH}$ protons from triglycerides within adipocytes. From these signals it is possible to obtain a relative $\%$ fat fraction (\%FF) of bone marrow as well as the relative level of unsaturation. Despite the rather limited number of signals arising from a typical ${ }^{1} \mathrm{H}$ MR spectrum of bone marrow, MRS has greatly improved understanding of the relationship between MAT and bone quality and function.

\section{<Figure 6 near here>}

Schellinger et al, published normative values of MAT in lumbar vertebral bone, showing that there is an age-dependent increase and that levels of MAT are genderdependent, with higher concentration being observed in males (Figure 7) ${ }^{35}$. They then went on to present data suggesting that \%FF may have predictive value in determining bone weakness, with elevated MAT levels being positively associated with increased long term vertebral weaknesses ${ }^{36}$. Indeed, MAT content is inversely correlated with bone mineral density (BMD) and is a strong predictor of bone integrity and function ${ }^{38,40}$. However, despite the association between MAT and BMD, ${ }^{1} \mathrm{H}-$ 
MRS of bone marrow is not predictive of the development or duration of lower-back pain $^{37}$.

<Figure 7 near here $>$

Recently, positive associations have been reported between MAT and visceral fat, ectopic fat and serum lipid, suggesting that similar factors may influence lipid deposition in all of these compartments ${ }^{41}$. However, no such association was found between overall adiposity and MAT ${ }^{42}$. Interestingly MAT is increased in patients with anorexia nervosa, characterized by extreme weight loss ${ }^{43}$, and MAT can recover to normal levels once weight is normalised ${ }^{33}$. There have also been studies of changes in MAT after gastric bypass surgery: following the large reductions in overall adiposity MAT also reduced, but interestingly only in non-diabetic subjects ${ }^{44}$. It seems that ${ }^{1} \mathrm{H}$ MRS is particularly well suited to the non-invasive study of this unique adipose tissue depot.

\subsection{Brown Adipose Tissue}

The discovery of brown adipose tissue (BAT) in adult human subjects by PET/CT has prompted a frenetic search for potential none-invasive methodologies that do not require the use of a radioactive tracer for its quantitation. Several MR alternatives have been put forward, including ${ }^{1} \mathrm{H}-\mathrm{MRS}$. 
BAT is a pivotal organ for the regulation of body thermogenesis in rodents and neonates. More recently, through the use of PET/CT, distinctive BAT depots have been identified in human adults. The presence of BAT has been shown to be inversely correlated to BMI, suggesting that it may play an important role in obesity. So far most of the in vivo work on BAT quantitation and function has been carried out using PET/CT, which has greatly limited human research. Several groups have attempted to utilize ${ }^{1} \mathrm{H}-\mathrm{MRS}$ to differentiate between white adipose tissue (WAT) and BAT in vivo based on their differences in cellular composition ${ }^{45-47}$. WAT consists mainly of adipocytes, with unilocular lipid droplets and limited intracellular water, while in BAT the adipocytes are smaller, multilocular and rich in metabolically active mitochondria and intracellular water.

However, despite these significant cellular differences, to date most of the research using ${ }^{1} \mathrm{H}$ MRS has only managed to show that WAT and BAT differ in level and composition of lipids and reduced water $T_{1}$ relaxation rates ${ }^{45-47}$. Using quantitative ${ }^{1} \mathrm{H}-\mathrm{MRS}, \mathrm{BAT}$ has been shown to have lower levels of fatty acid unsaturation and polyunsaturation, decreasing even further during BAT stimulation through cold exposure or norepinephrine administration. Furthermore, the unsaturation index of BAT has been shown to be inversely related to the age of the volunteer, confirming previous in vitro studies. Similarly, Peng et al showed that WAT had a higher FF than BAT, but that difference depended on the genetic strain of the mice ${ }^{48}$. Ob/ob and Fsp27 gene knock-out mice, genetic models of severe obesity, showed similar differences in FF between WAT and BAT as seen in wild-type, while no differences were observed in SKO mice, suggesting differences regulatory effects of the ob, seipin and Fsp27 genes on the development of WAT and BAT ${ }^{48}$. 
Overall, the impact of in vivo ${ }^{1} \mathrm{H}-\mathrm{MRS}$ on the study of $\mathrm{BAT}$, both from a quantitative and functional point of view, has been rather limited. Much more promising are the results arising from the use of MRI to differentiate and quantitate BAT from WAT30,49. Both, relaxometry-based $\left(T_{1}, T_{2}\right)$ and chemical shift-based approaches appear quite promising, yet further validation is required before MRI and MRS methods can replace PET/CT for the study of BAT in human subjects.

In conclusion, MRS techniques have contributed greatly to our understanding of adipose tissue function in humans and animal models, especially in the area of fat composition and ectopic fat deposition. However, compared to MRI techniques, it has had a rather limited impact on our understanding of the factors that determine body fat content and distribution. As such, MRS is likely to continue to be an adjunct to more accurate and sophisticated imaging techniques.

\subsection{Related Articles}

emrstm0014

Animal Methods in MRS

emrstm0518

Spatial Localization Techniques for Human MRS

emrstm1431;

Muscle studies by $1 \mathrm{H}$ MRS

emrstm1436

In vivo MRS of lipids in adipose tissue, bone marrow and liver 
emrstm1462

Insulin resistance, type 2 diabetes and obesity and other metabolic disorders studied by MRS emrstm1470

Monitoring fatty liver \& other hepatic diseases

emrstm 1480

Direct imaging methods: Chemical-selective MRI and the Dixon method

emrstm1485

The Basics: Basics of NMR spectroscopy and SNR and in vivo MRS 


\section{References}

1. E.L. Thomas, G. Frost, S.D. Taylor-Robinson, and J.D. Bell. Nutr. Res. Rev. 2012, 25, 150.

2. E.L. Thomas, J.A. Fitzpatrick, S.J. Malik, S.D. Taylor-Robinson, and J.D. Bell. Prog. Nucl. Magn. Reson. Spectrosc. 2013, 73, 56.

3. D.A. Wood, S. Butler, R.A. Riemersma, M. Thomson, M.F. Oliver, M. Fulton, A. Birtwhistle, and R. Elton. Lancet. 1984, 324, 117.

4. D.A. Wood, R.A. Riemersma, S Butler, M Thomson, C Macintyre, R.A. Elton, and M.F. Oliver. Lancet. 1987 329, 177.

5. P. Canioni, J.R. Alger, and R.G. Shulman. Biochemistry. 1983, 22, 4974.

6. T.W. Fan, A.J. Clifford, and R.M. Higashi. J. Lipid Res. 1994, 35, 678.

7. C.T. Moonen, R.J. Dimand, and K.L. Cox. Magn. Reson. Med. 1988, 6, 140.

8. N. Beckmann, J.J. Brocard, U. Keller, and J. Seelig. Magn. Reson. Med. 1992, 27, 97.

9. E.L. Thomas, G. Frost, M.L. Barnard, D.J. Bryant, S.D. Taylor-Robinson, J. Simbrunner, G.A. Coutts, M. Burl, S.R. Bloom, K.D. Sales, and J.D. Bell. Lipids. 1996, 31, 145.

10. J.H. Hwang, S. Bluml, A. Leaf, and B.D. Ross. NMR Biomed. 2003, 16, 160.

11.R.J. Dimand, C.T. Moonen, S.C. Chu, E.M. Bradbury, G. Kurland, and K.L. Cox. Pediatr. Res. 1988, 24, 243.

12.E.L. Thomas, S.D. Taylor-Robinson, M.L. Barnard, G. Frost, J. Sargentoni, B.R. Davidson, S.C. Cunnane, and J.D. Bell. Hepatology. 1997, 25, 178-83.

13.E.L. Thomas, J.D. Hanrahan, M. Ala-Korpela, G. Jenkinson, D. Azzopardi, R.A. Iles, and J.D. Bell. Lipids. 1997, 32, 645.

14.E.L. Thomas, S.C. Cunnane, and J.D. Bell. NMR Biomed. 1998, 11, 290. 
15. J. Lundbom, S. Heikkinen, B. Fielding, A. Hakkarainen, M.R. Taskinen, and N. Lundbom. J. Magn. Reson. 2009, 201, 39.

16. J. Machann, N. Stefan, C. Schabel, E. Schleicher, A. Fritsche, C. Würslin, H.U. Häring, C.D. Claussen, and F. Schick. NMR Biomed. 2013, 26, 232.

17.J. Lundbom, A. Hakkarainen, N. Lundbom, and M.R. Taskinen. Int. J. Obes. 2013, 37, 620.

18. B. Querleux, C. Cornillon, O. Jolivet, and J. Bittoun. Skin Res. Technol. 2002, 8, 118.

19. P. Mystkowski, E. Shankland, S.A. Schreyer, R.C. LeBoeuf, R.S. Schwartz, D.E. Cummings, M. Kushmerick, M.W. Schwartz. Int. J. Obes. Relat. Metab. Disord. 2000, 24, 719.

20. A.D. Mitchell, P.C. Wang, R.W. Rosebrough, T.H. Elsasser, W.F. and Schmidt. Poult. Sci. 1991, 70, 2494.

21.D.T. Stein, E.E. Babcock, C.R. Malloy, and J.D. McGarry. Int. J. Obes. Relat. Metab. Disord. 1995, 19, 804.

22. M. Barac-Nieto, and R.K. Gupta. J. Magn. Reson. Imaging. 1996, 6, 235.

23. A Lirette, RA Towner, Z Liu, EG Janzen, JR Chambers, RW Fairfull, LP Milligan, DC Crober. Poult. Sci. 1993, 72, 1411.

24. L. Calderan, P. Marzola, E. Nicolato, P.F. Fabene, C. Milanese, P. Bernardi, A. Giordano, S. Cinti, A. Sbarbati. Obesity 2006, 14, 405.

25. I. Cavallini, M.A. Marino, C. Tonello, P. Marzola, E. Nicolato, P.F. Fabene, L. Calderan, P. Bernardi, R.M. Asperio, E. Nisoli, A. Sbarbati. Biomed. Pharmacother. 2006, 60, 139.

26. M. Kamba, S. Meshitsuka, N. Iriguchi, M. Koda, K. Kimura, and T. Ogawa. J. Magn. Reson. Imaging. 2000, 11, 330. 
27. M. Kamba, K. Kimura, M. Koda, and T. Ogawa. Am. J. Clin. Nutr. 2001, 73, 172.

28. J. Weis, and A. Hemmingsson. Magn. Reson. Imaging. 2001, 19, 1239.

29. B.E. Walling, J. Munasinghe, D. Berrigan, M.Q. Bailey, and R.M. Simpson. Obesity. 2007, 15, 69.

30.H.H. Hu, and H.E. Kan. NMR Biomed. 2013, 26, 1609

31.K.D. Patel, K.W. Abeysekera, M. Marlais, M.J. McPhail, H.C. Thomas, J.A. Fitzpatrick, A.K. Lim, S.D. Taylor-Robinson, and E.L. Thomas. Expert Rev. Gastroenterol. Hepatol. 2011, 5, 91.

32. R. Banerjee, M. Pavlides, E.M. Tunnicliffe, S.K. Piechnik, N. Sarania, R. Philips, J.D. Collier, J.C. Booth, J.E. Schneider, L.M. Wang, D.W. Delaney, K.A. Fleming, M.D. Robson, E. Barnes, S. Neubauer. J. Hepatol. 2014, 60, 69.

33. MJ Devlin, and CJ Rosen. Lancet Diabetes Endocrinol. 2015, 3, 141.

34. F. Schick, H. Bongers, W.I. Jung, M. Skalej, O. Lutz, and C.D. Claussen. Magn. Reson. Med. 1992, 26, 207.

35. D. Schellinger, C.S. Lin, D. Fertikh, J.S. Lee, W.C. Lauerman, F. Henderson, B. and Davis. Radiology. 2000, 215, 910.

36.D. Schellinger, C.S. Lin, H.G. Hatipoglu, and D. Fertikh. Am. J. Neuroradiol. 2001, 22, 1620.

37.D.G. Borenstein, J.W. O'Mara Jr, S.D. Boden, W.C. Lauerman, A. Jacobson, C. Platenberg, D. Schellinger, S.W. Wiesel. J. Bone Joint Surg. Am. 2001, 83, 1306.

38.P.K. Fazeli, M.C. Horowitz, O.A. MacDougald, E.L. Scheller, M.S. Rodeheffer, C.J. Rosen, and A. Klibanski. J. Clin. Endocrinol. Metab. 2013, 98, 935.

39. E.L. Scheller and C.J. Rosen. Annals New York Acad. Sci. 2014, 1311, 14 
40. M.A. Bredella, E. Lin, A.V. Gerweck, M.G. Landa, B.J. Thomas, M. Torriani, M.L. Bouxsein, and K.K. Miller. J. Clin. Endocrinol. Metab. 2012, 97, 4115.

41. M.A. Bredella, C.M. Gill, A.V. Gerweck, M.G. Landa, V. Kumar, S.M. Daley, M. Torriani, and K.K. Miller. Radiology. 2013, 269, 534.

42. Y. Sheu, and J.A. Cauley. Curr. Osteoporos. Rep. 2011, 9, 67.

43. M.A. Bredella, P.K. Fazeli, S.M. Daley, K.K. Miller, C.J. Rosen, A. Klibanski, and M. Torriani. Bone. 2014, 66, 199.

44.A.L. Schafer, X. Li, A.V. Schwartz, L.S. Tufts, A.L. Wheeler, C. Grunfeld, L. Stewart, S.J. Rogers, J.T. Carter, A.M. Posselt, D.M. Black, and D.M. Shoback. Bone. 2015, 74, 140-5.

45. C. Zancanaro, R. Nano, C. Marchioro, A. Sbarbati, A. Boicelli, and F. Osculati. J. Lipid Res. 1994, 35, 2191.

46. K. Strobel, J. van den Hoff, and J. Pietzsch. J. Lipid Res. 2008, 49, 473.

47.G. Hamilton, D.L. Smith Jr, M. Bydder, K.S. Nayak, and H.H. Hu. J. Magn. Reson. Imaging. 2011, 34, 468.

48. X.G. Peng, S. Ju, F. Fang, Y. Wang, K. Fang, X. Cui, G. Liu, P. Li, H. Mao, and G.J. Teng. Am. J. Physiol. Endocrinol. Metab. 2013, 304, E160.

49. Y.C. Chen, A.M. Cypess, Y.C. Chen, M. Palmer, G. Kolodny, C.R. Kahn, and K.K. Kwong. J. Nucl. Med. 2013, 54, 1584. 
Table 1. Assignment and Frequencies of Resonances in a Coupled ${ }^{13} \mathrm{C}$ NMR Spectrum of in Vivo Human Adipose Tissue

\begin{tabular}{|c|c|c|c|}
\hline Peak & Splitting & Assignment & Chemical Shift (ppm) \\
\hline 1 & singlet & $-\mathrm{CH}_{2}{ }^{-\star} \mathrm{CO}$ & 172.1 \\
\hline \multirow[t]{2}{*}{$2+4$} & doublet & $-{ }^{*} \mathrm{CH}=\mathrm{CH}-\mathrm{CH}_{2}-$ & 134.9 and $125.4^{a}(130.0)^{b}$ \\
\hline & & $\mathrm{CH}={ }^{*} \mathrm{CH}-$ & \\
\hline \multirow[t]{2}{*}{$3+5$} & doublet & $-\mathrm{CH}={ }^{\star} \mathrm{CH}-\mathrm{CH}_{2}-$ & 133.4 and $124.2(128.4)$ \\
\hline & & ${ }^{*} \mathrm{CH}=\mathrm{CH}-$ & \\
\hline $6+8$ & doublet & C2 glycerol & 69.2 and 68.1 (69.5) \\
\hline $7,9,10$ & triplet & $\mathrm{C} 1+\mathrm{C} 3$ glycerol & $62.9,61.7$ and $60.6(62.2)$ \\
\hline 11,15 & triplet & $-\mathrm{CH}_{2}-* \mathrm{CH}_{2}-\mathrm{CO}$ & $42.9,34.8$ and $x(34.2)$ \\
\hline 12,16 & triplet & $-{ }^{*} \mathrm{CH}_{2}-\mathrm{CH}_{2}-\mathrm{CH}_{3}$ & $41.0,33.4$ and $x(32.3)$ \\
\hline $13,17,20$ & triplet & $-\left({ }^{\star} \mathrm{CH}_{2}\right) \mathrm{n}^{-}$ & $38.7,30.8$ and 22.9 (30.1) \\
\hline \multirow[t]{3}{*}{$14,18,21$} & triplet & $-\mathrm{CH}=\mathrm{CH}-{ }^{*} \mathrm{CH}_{2}-\mathrm{CH}_{2}-$ & $36.2,28.3,20.6(27.6)$ \\
\hline & triplet & $-\mathrm{CH}=\mathrm{CH}-{ }^{\star} \mathrm{CH}_{2}-$ & $x, x, x(25.5)$ \\
\hline & & $\mathrm{CH}=\mathrm{CH}-$ & \\
\hline \multirow[t]{2}{*}{23} & triplet & $-{ }^{\star} \mathrm{CH}_{2}-\mathrm{CH}_{2}-\mathrm{CO}$ & $\mathrm{x}, \mathrm{x}$ and $16.2(25.2)$ \\
\hline & triplet & $-\mathrm{CH}_{2}-{ }^{*} \mathrm{CH}_{2}-\mathrm{CH}_{3}$ & $x, x, x(23.1)$ \\
\hline
\end{tabular}


19,22,24,25 quartet $\quad \mathrm{CH}_{2}{ }^{-} \mathrm{CH}_{3}$

$3.36,11.2,18.9,26.7$

$(14.2)$

Notes: ${ }^{2}$ Values refer to resonance position in the coupled ${ }^{13} \mathrm{C}$ NMR spectrum; bSingle values in parentheses refer to resonance position in the decoupled ${ }^{13} \mathrm{C}$ NMR spectrum. xPeak cannot be resolved in the coupled spectrum due to overlapping resonances 


\section{Figure Captions}

Figure 1. Non-localized, fully relaxed, ${ }^{1} \mathrm{H}$-coupled ${ }^{13} \mathrm{C}$-spectrum of adipose tissue from a healthy adult volunteer. The spectrum was acquired from the right thigh of the volunteer on a 1.T system (Phillips; Netherland), using a $10 \mathrm{~cm}$ surface coil, in approximately 4 minutes with a TR of 30s. Details of peak assignment are shown in Table 1.

Figure 2: (a) Chemical groups of a triglyceride molecule with chemical shift, assignment and name of the corresponding resonance. (b) In vivo spectrum (right) of visceral adipose tissue from the MRI voxel location (left) with the peaks labeled (adapted from Ref. 14).

Figure 3. Typical ${ }^{1} \mathrm{H}$ MR spectra from mice with varying levels of adiposity. The fat peak (right side) increases relative to the water with increasing adiposity.

Figure 4: ${ }^{1} \mathrm{H}$ MR spectra from different parts of the body of a female $(\mathrm{A})(\mathrm{BMI}=23.7$ $\left.\mathrm{kg} / \mathrm{m}^{2}\right)$ and male $(\mathrm{B})\left(\mathrm{BMl}=21 \mathrm{~kg} / \mathrm{m}^{2}\right)$ volunteer, with accompanying silhouette to demonstrate slab position (adapted from 26).

Figure 5. Typical MR coronal images obtained from a group of healthy female volunteers. Images were acquired on a $1.5 \mathrm{~T}$ system using a $\mathrm{T}_{1}$-weighted imaging 
sequence using a series of scanning blocks $(n=9-12)$ to for a head-to-toe coverage. The volunteers are ordered according to their self-reported UK clothes sizes (UK size 6 - UK size 20), with corresponding BMI from left to right of $20.4 \mathrm{~kg} / \mathrm{m}^{2}, 18.7$ $\mathrm{kg} / \mathrm{m}^{2}, 21.9 \mathrm{~kg} / \mathrm{m}^{2}, 23.0 \mathrm{~kg} / \mathrm{m}^{2}, 25.7 \mathrm{~kg} / \mathrm{m}^{2}, 27.3 \mathrm{~kg} / \mathrm{m}^{2}, 34.9 \mathrm{~kg} / \mathrm{m}^{2}$, and $32.2 \mathrm{~kg} / \mathrm{m}^{2}$.

Figure 6. Comparison of $(A)$ normal bone in a healthy teenage girl and $(B)$ a patient with vertical disc herniations at the inferior endplates of $L 2$ and $L 3$. The ${ }^{1} \mathrm{H}$ MRS shows the lipid peak (right) to be much higher than the water peak (left). In (A) the percentage fat fraction (\%FF) was estimated at 16 ; in (B) the \%FF was significantly higher, 64. (Adapted from Ref. 36).

Figure 7. MAT fraction of both normal and abnormal bone marrow increases with age. Abnormal bone has a higher \%FF in all age groups (Adapted from Ref. 36). 
Figure 1

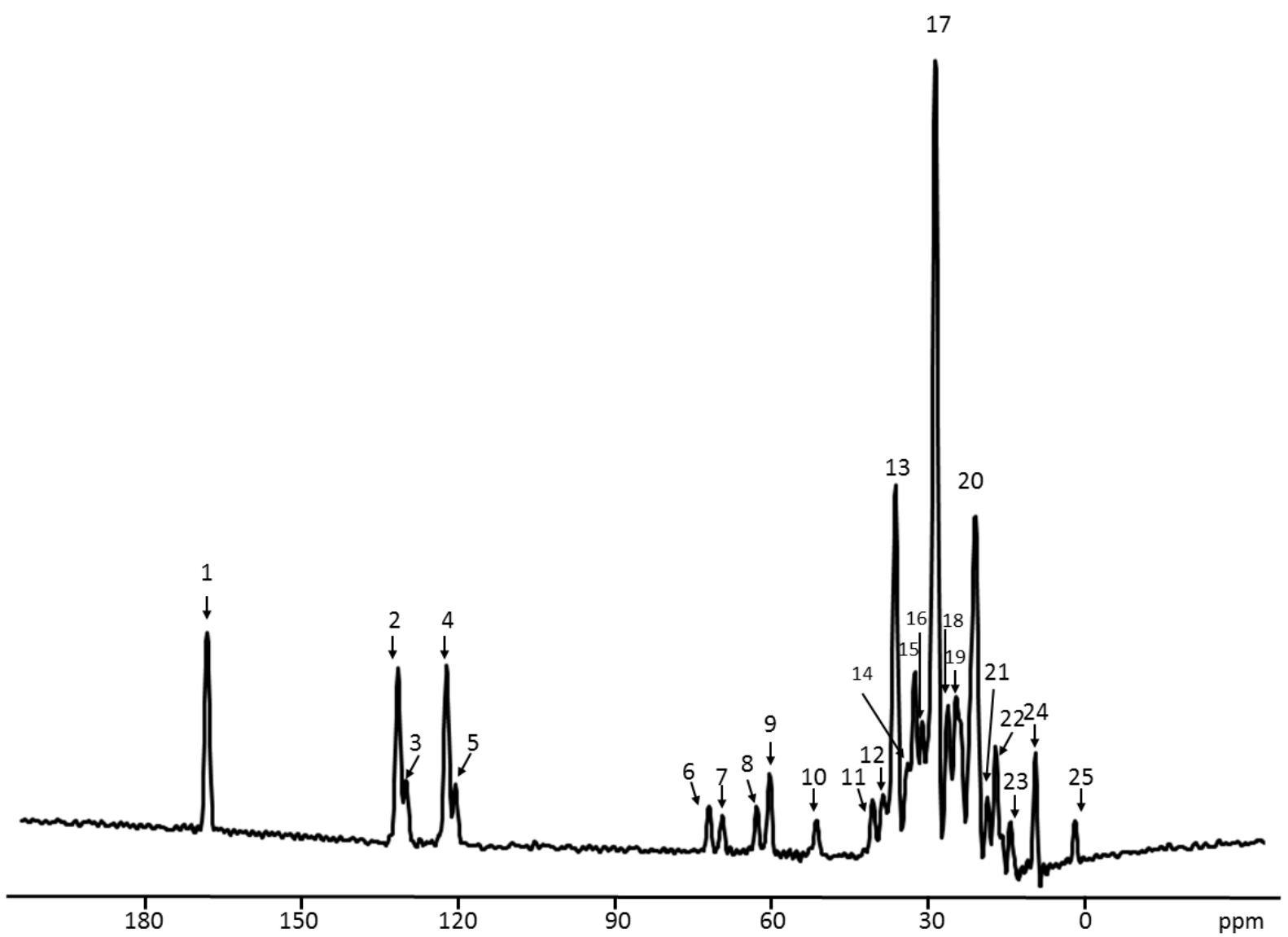


Figure 2
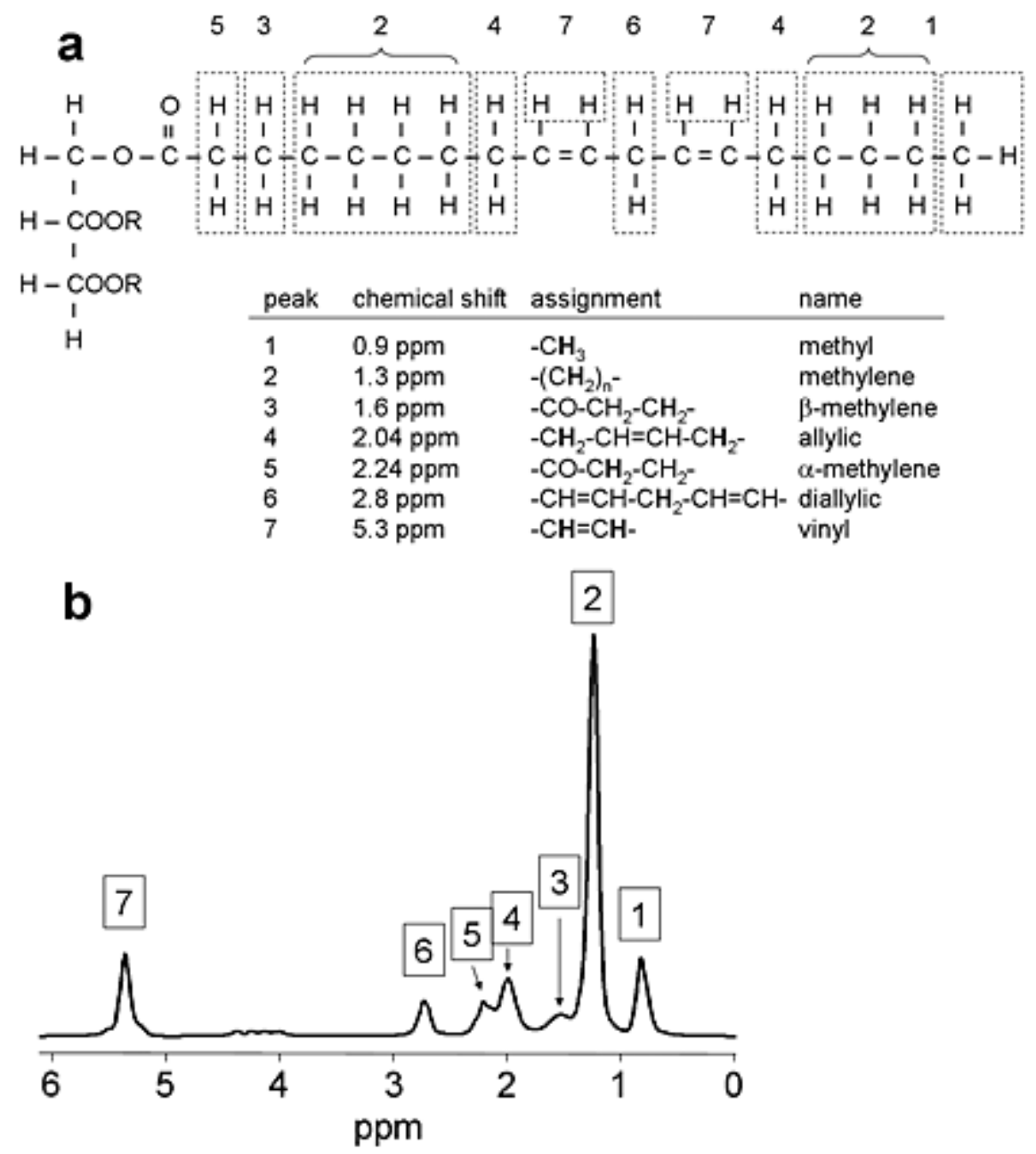
Figure 3

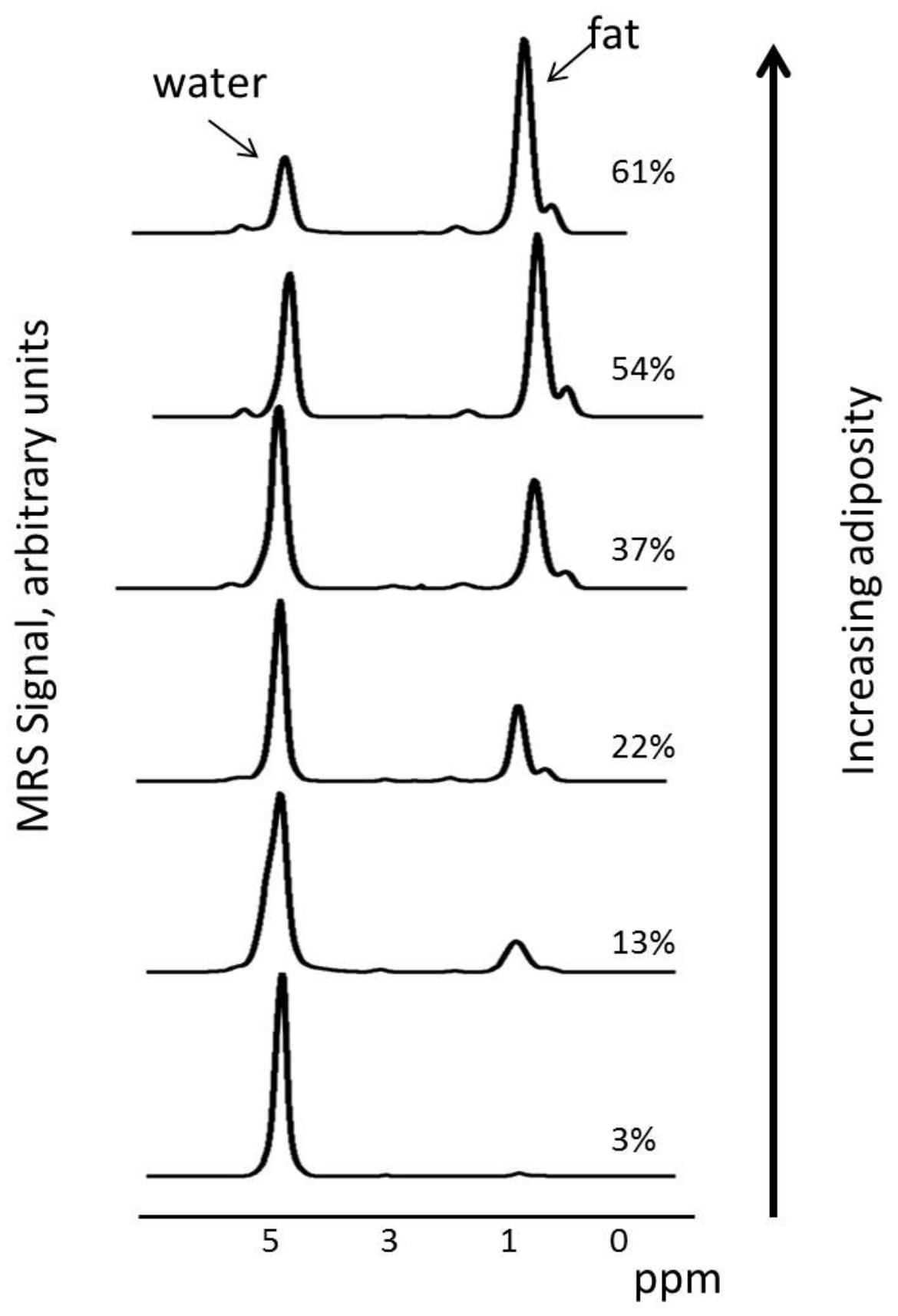

Figure 4 

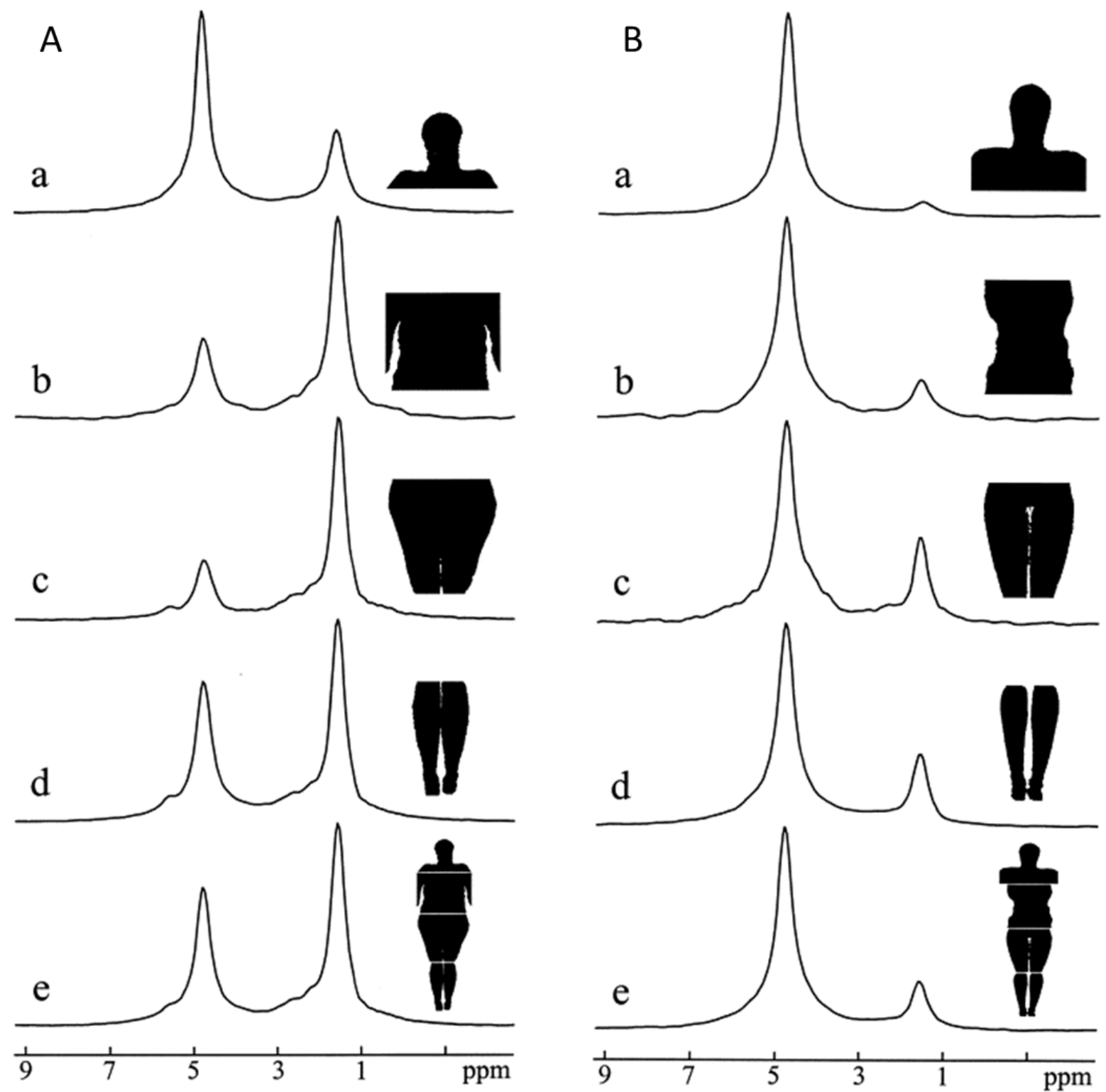

Figure 5 


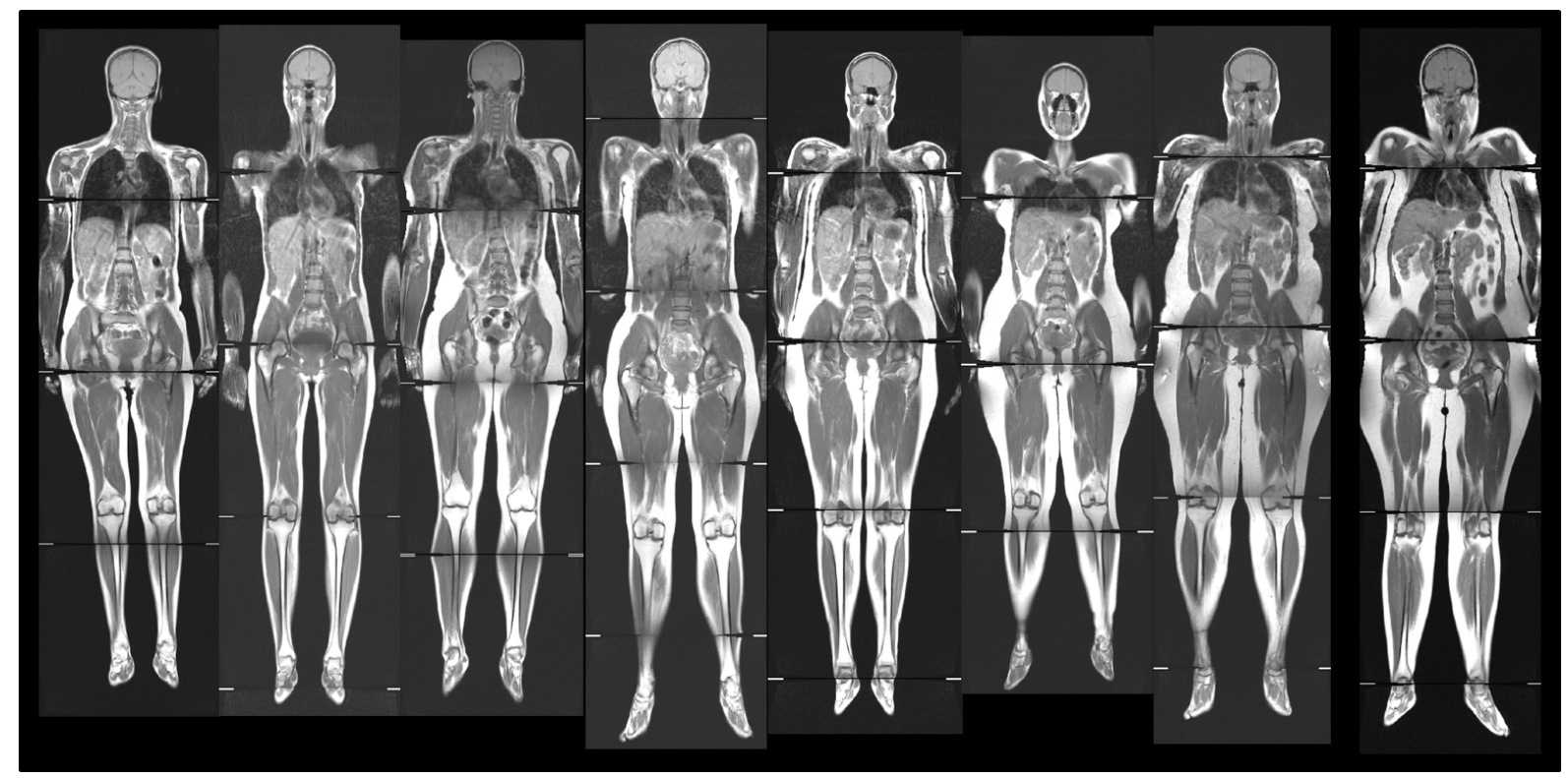

Figure 6
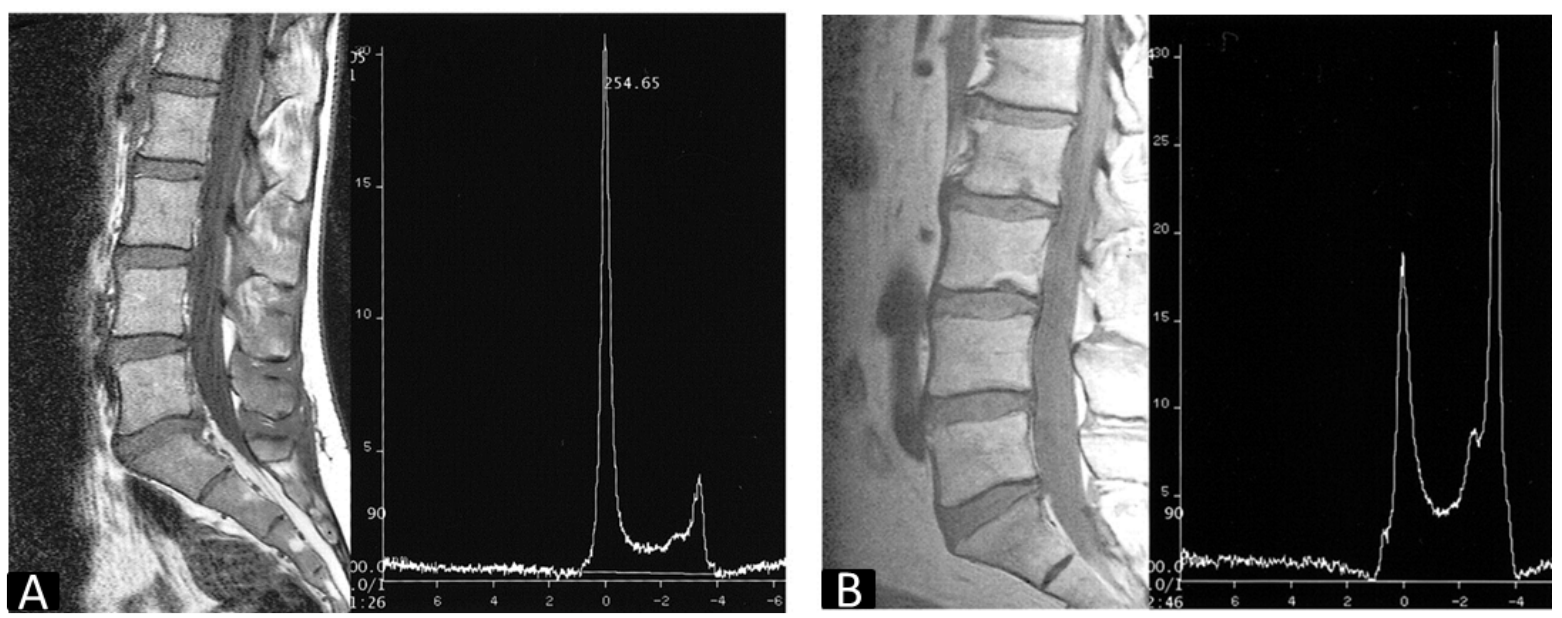

Figure 7 


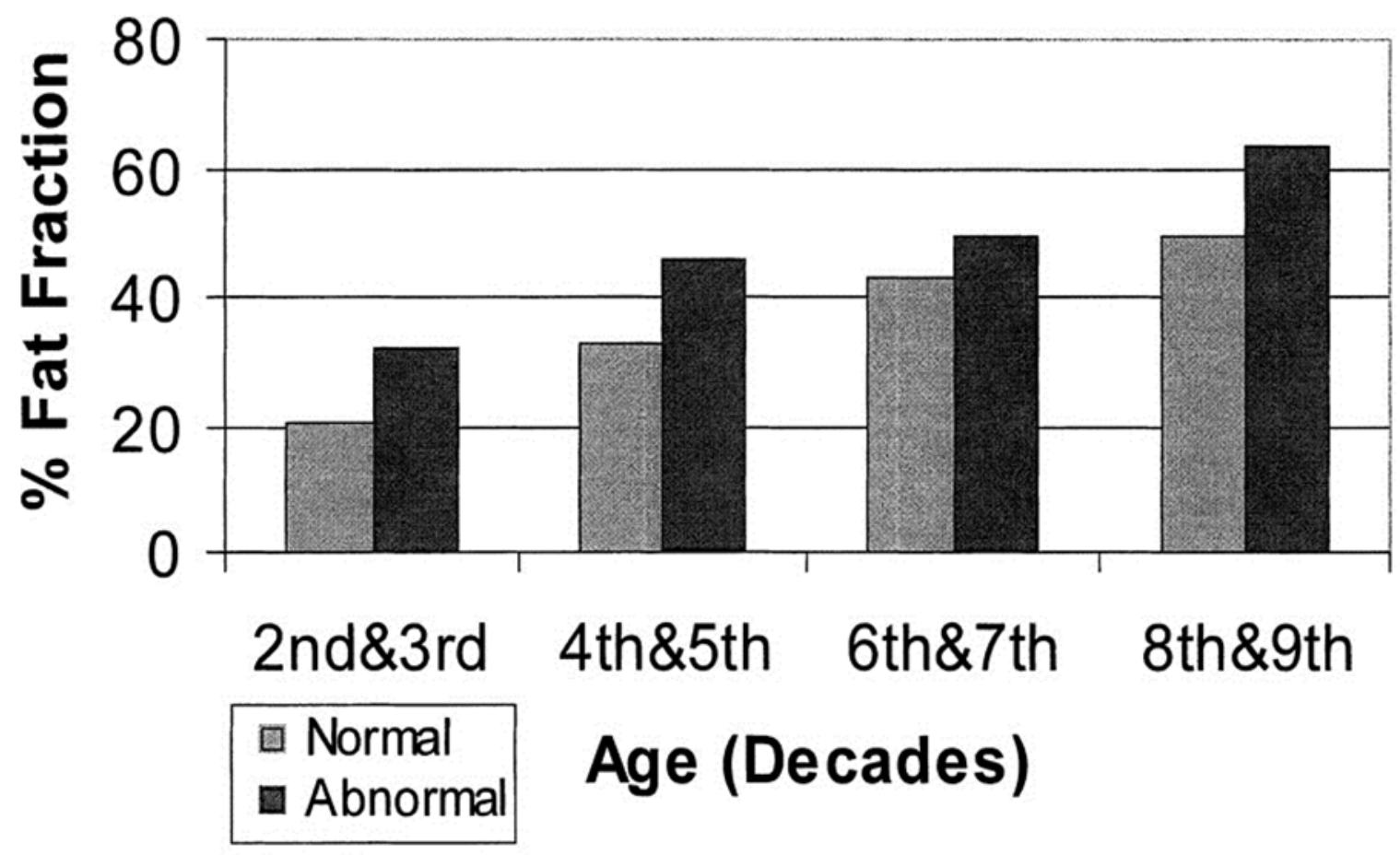

